\title{
Oxalate nephropathy from cashew nut intake
}

\author{
Margarida Bernardino BHSc RD, Malvinder S. Parmar MB MS
}

Cite as: CMAJ 2017 March 13;189:E405-8. doi: 10.1503/cmaj.151327

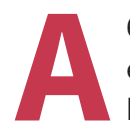

63-year-old woman was referred to a nephrologist for evaluation of decreased kidney function. The patient had no specific urinary symptoms or history of recurrent urinary tract infections, leg edema or kidney stones. She did not have nausea, vomiting, diarrhea or symptoms of steatorrhea, and had not been using anti-inflammatory agents. Her past medical history included gastresophageal reflux disease, chronic constipation, depression and remote left frontal lobe resection for benign tumour. Her medications included citalopram (20 mg daily), omeprazole (20 mg daily) and risperidone (3 $\mathrm{mg}$ at bedtime).

Her physical examination was unremarkable, including normal blood pressure. Laboratory test results showed an elevated serum creatinine level of 172 (normal 35-97) $\mu \mathrm{mol} / \mathrm{L}$ and urea level of 11.2 (normal 2-8) $\mathrm{mmol} / \mathrm{L}$; eight months earlier, her levels were $71 \mu \mathrm{mol} / \mathrm{L}$ and $5.7 \mathrm{mmol} / \mathrm{L}$, respectively (Appendix 1, available at www.cmaj.ca/lookup/ suppl/doi:10.1503/cmaj.151327/-/ DC1). Urinalysis was negative for protein, and no active sediment or crystals were reported. Abdominal ultrasonography showed bilateral echogenic kidneys with incidental gallstones. Serum immunoelectrophoresis showed a monoclonal band of IgG kappa measuring 9.3 (normal 6.3-14.9) g/L. These findings and the presence of anemia (hemoglobin 88 [normal 120$160] \mathrm{g} / \mathrm{L}$ ) led us to consider paraproteinemia, which was ruled out by a normal result for bone marrow aspiration.

The progressive decline in kidney function raised the possibility of light-chain nephropathy, and a kidney biopsy was performed three months after presentation to the nephrologist that showed acute tubular necrosis and calcium oxalate crystals consistent with oxalate nephropathy (Figure 1).

At that time, the patient's serum creatinine level was $234 \mu \mathrm{mol} / \mathrm{L}$, with a urea level of
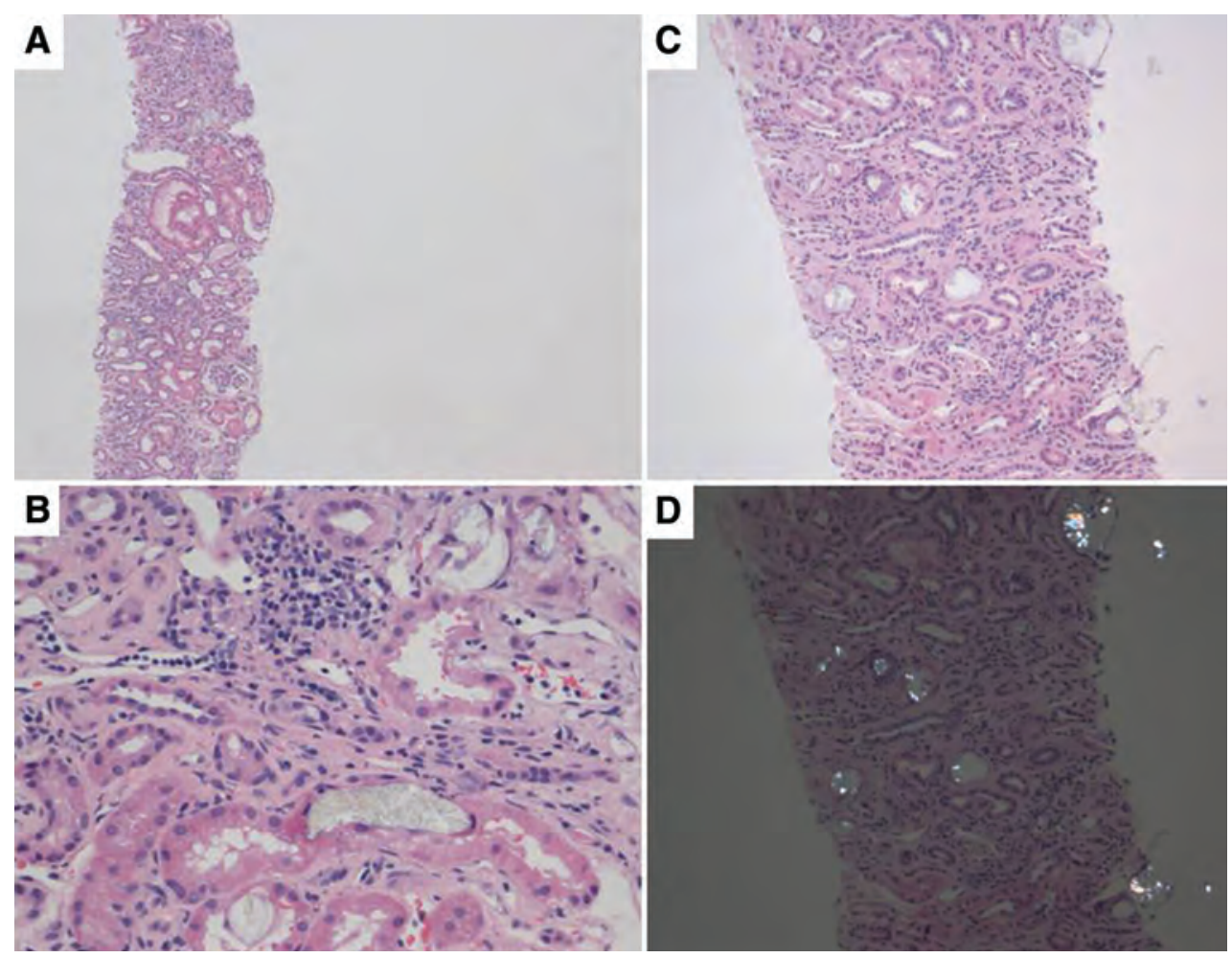

Figure 1: Photomicrographs of the kidney biopsy in a 63-year-old woman with kidney injury. (A) Shrunken glomeruli and diffuse tubular degenerative change, including many pale-stained crystals and mild interstitial inflammation. Original magnification x 5. (B) View of tubular crystals mostly located in the cytoplasm of tubular cells. Original magnification $\times 20$. Identical images of these crystals under (C) regular and (D) polarized light showing characteristic birefringence. Original magnification $\times 10$. 
(55 [normal 20-96] nmol/L), and no other factors associated with hyperoxaluria, such as vitamin $\mathrm{C}$ supplementation, were identified.

The patient was referred to a renal dietitian for an assessment of oxalate content in the patient's typical diet. The dietitian discovered that the patient had started eating a can ( 275 g per can)

Box 1: The patient's typical daily intake of oxalate and calcium ${ }^{\star}$ from food

\begin{tabular}{|c|c|c|}
\hline Food & Oxalate content, mg & Calcium, ${ }^{\star}$ mg \\
\hline Milk (250 mL) & 2 & 309 \\
\hline Egg (2) & 5 & 87 \\
\hline White bread slice (2) & 10 & 84 \\
\hline Oatmeal ( 75 g cooked) & 25 & 63 \\
\hline Mushrooms (125 mL) & 5 & 5 \\
\hline Cashews (100-150 g) & $260-325$ & 46 \\
\hline $\begin{array}{l}\text { Potatoes, mashed } \\
(125 \mathrm{~mL})\end{array}$ & 25 & 4 \\
\hline Ham steak (1) & 2 & 3 \\
\hline Coffee $(250 \mathrm{~mL})$ & 5 & 5 \\
\hline Total intake per day & $339-409$ & 606 \\
\hline RDA per day & $\begin{array}{c}\text { No clear } \\
\text { recommendations } \dagger\end{array}$ & $1200 \ddagger$ \\
\hline \multicolumn{3}{|c|}{$\begin{array}{l}\text { Note: RDA = Recommended Dietary Allowance. } \\
\text { *Values obtained from food searches in the Canadian Nutrient File (https://food } \\
\text {-nutrition.canada.ca/cnf-fce/index-eng.jsp). } \\
\text { †There is no daily RDA for oxalate, because oxalate is an antinutrient. In the } \\
\text { United States, oxalate intake is estimated to average between } 150 \text { and } 200 \mathrm{mg} / \mathrm{d} .^{7} \\
\text { The American Academy of Nutrition and Dietetics recommends limiting dietary } \\
\text { intake of oxalates to < } 50 \mathrm{mg} / \mathrm{d} \text { in patients with oxalate kidney stones } \\
\text { (www.eatrightpro.org). } \\
\text { fDietary Reference Intakes for vitamin D and calcium. Health Canada } \\
\text { (http://www.hc-sc.gc.ca/fn-an/nutrition/vitamin/vita-d-eng.php\#a7). }\end{array}$} \\
\hline
\end{tabular}

\section{Box 2: Primary hyperoxaluriaa,}

Primary hyperoxaluria ( $\mathrm{PH}$; autosomal recessive inherited disorders):

- Type 1 (PH1) (80\% of all PH)

- Decreased or absent activity of vitamin $\mathrm{B}_{6}$-dependent hepatic peroxisomal enzyme (alanine-glyoxylate aminotransferase [AGXT]); AGXT gene located on chromosome 2

- Failure to transaminate glyoxylate that results in increased urinary excretion of oxalate and glycolate

- Type 2 (PH2) (10\% of all PH)

- Mutation in the glyoxylate/hydroxypyruvate reductase gene (GRHPR) that is located on chromosome 10

- Reduced GRHPR activity leads to increased bioavailability of lactate and hydroxypyruvate for conversion of oxalate and L-glycerate

- Characterized by increased urinary excretion of L-glycerate

- Type 3 (PH3) (about $10 \%$ of all PH)

- Mutation in the mitochondrial dihydrodipicolinate synthaselike gene (HOGAl)

- Commonly presents as nephrolithiasis of cashews every two days (about 100-150 g per day or about $1 \mathrm{~kg}$ of cashews per week) for their "laxative effect," about four months before her first visit to the nephrologist, after she learned from a television show that cashews were a "healthy food" and may help relieve constipation. The patient had found the cashews to be very helpful in this regard, and started eating them every day. The patient's diet was poor in other nutrients, most notably calcium (Box 1).

The patient was advised to stop consuming cashews to limit the intake of oxalates to less than $50 \mathrm{~g}$ per day. Calcium carbonate (500 mg twice a day) was added with meals to act as an oxalate binder and to ensure appropriate calcium intake. Two months after following these recommendations, the patient's urinary oxalate excretion had normalized $(88 \mu \mathrm{mol} / \mathrm{d})$ and her kidney function had improved (serum creatinine $184 \mu \mathrm{mol} / \mathrm{L}$ ). Although the patient's kidney function continued to improve, she was left with residual chronic kidney disease (serum creatinine $130 \mu \mathrm{mol} / \mathrm{L}$ ) eight months after stopping the cashews (Appendix 1).

\section{Discussion}

Oxalate, an antinutrient, is a conjugated anion of oxalic acid. It is ubiquitous in nature and is derived from various animal and plant sources. There are two main sources of oxalate: endogenous production in the liver from metabolism of its precursors (hydroxyproline, glycine and serine) and gastrointestinal absorption of oxalates in the diet. The oxalate content of a typical Western diet is approximately $80-120 \mathrm{mg}$ per day, about $10 \%$ of which is absorbed via the gastrointestinal tract. ${ }^{1}$ Oxalate is not metabolized in humans and is excreted unchanged in urine. The normal daily urinary excretion of oxalate ranges between 40 and $320 \mu \mathrm{mol} / \mathrm{d}$. Urinary excretion of oxalate above this range is classified as hyperoxaluria. ${ }^{2}$

\section{Pathogenesis of hyperoxaluria}

Hyperoxaluria ${ }^{2}$ may be primary or secondary. Primary hyperoxaluria results from an inherited defect in oxalate metabolism that results in increased endogenous production of oxalate (Box 2). ${ }^{2,3}$ Secondary hyperoxaluria may result from either dietary excess, enteric hyperabsorption (Figure 2), or enhanced endogeneous production resulting from exposure to its precursors (ascorbic acid) or from pyridoxine deficiency. The absorption of oxalate in the gastrointestinal tract is influenced by many factors, including gut health and function, ${ }^{4}$ oxalate intake or oxalate content of food $^{5}$ (Appendix 2, available at www.cmaj.ca/lookup/suppl/ doi:10.1503/cmaj.151327/-/DC1) and, most importantly, the intake of other nutrients such as calcium, magnesium and fat. ${ }^{1}$ High levels of dietary calcium ${ }^{6}$ and magnesium ${ }^{7}$ inhibit oxalate absorption through formation of insoluble oxalate salts in the gastrointestinal tract that are poorly absorbed. In addition, food preparation can affect oxalate absorption, as seen with "juicing." Juices are concentrated forms of fruits and vegetables that may have high amounts of oxalate. Consequently, the increased amount of fluid load in the juices can promote paracellular absorption of oxalate in the intestines. ${ }^{8}$ The bioavailability of the oxalate in the meal is more important than its amount. 


\section{Consequences of hyperoxaluria}

Hyperoxaluria, whether primary or secondary, can cause nephrolithiasis. However, it can also cause crystalline nephropathy through deposition of calcium oxalate crystals in the renal parenchyma that cause tubular damage, interstitial inflammation and fibrosis, and may present as acute kidney injury or chronic kidney disease. ${ }^{3}$ In patients with chronic diarrhea, the associated volume depletion and metabolic acidosis results in low urinary $\mathrm{pH}$ and hypocitraturia

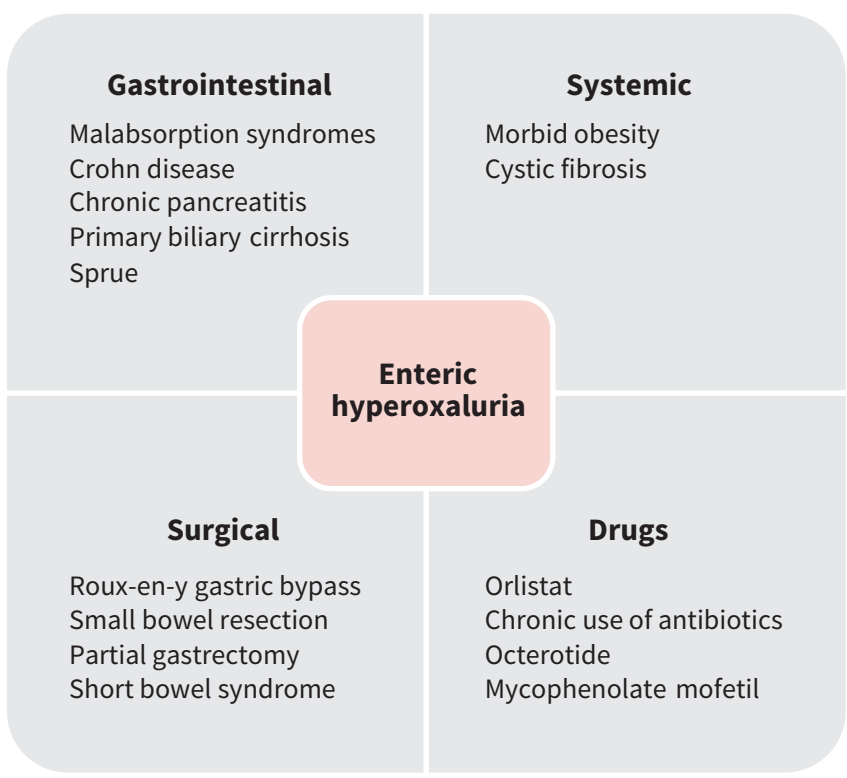

Figure 2: Causes of enteric hyperoxaluria. ${ }^{2,3}$

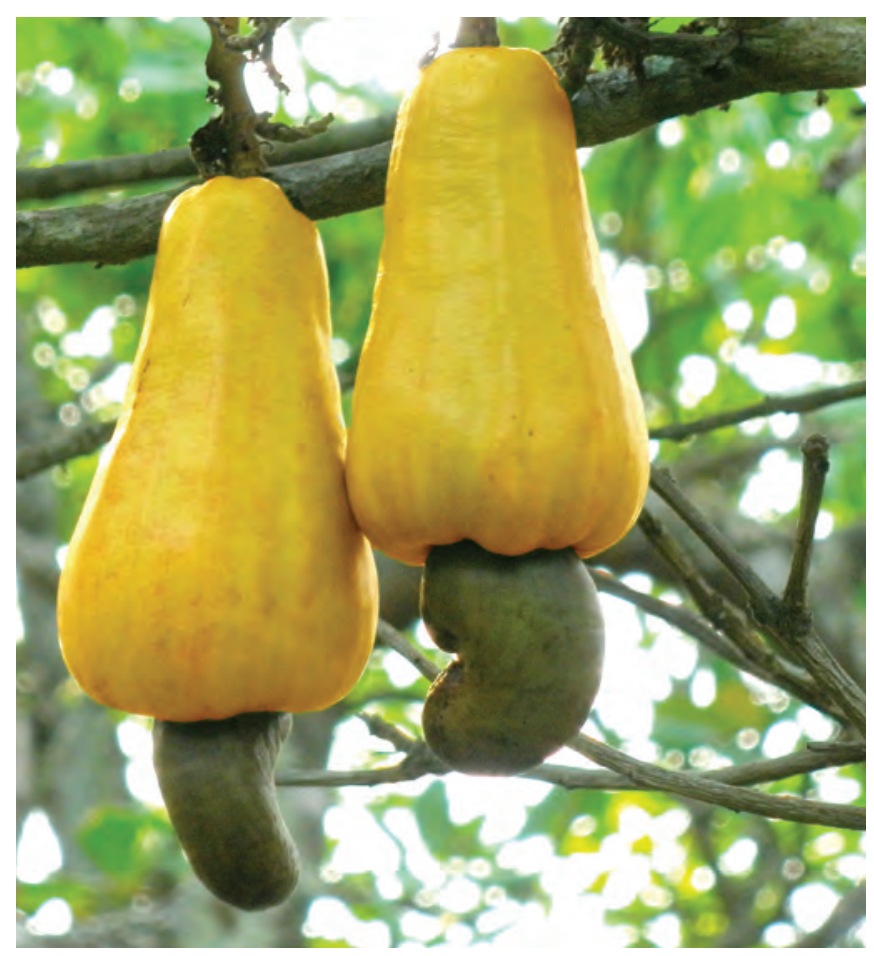

Figure 3: Cashew apple with seeds (nuts) (available at https://en.wikipedia. org/wiki/Cashew). By Abhishek Jacob (own work) [CC BY-SA 3.0 (http:// creativecommons.org/licenses/by-sa/3.0)] via Wikipedia Commons. that, in conjunction with hyperoxaluria, potentiate calcium oxalate precipitation in the kidney and promote kidney injury. ${ }^{3}$ Oxalate nephropathy has been reported with excessive consumption of different oxalate-rich foods, ${ }^{3}$ including nuts and iced tea.

Cashew nuts (actually seeds) are attached to the bottom of the cashew apple (Figure 3), the fruit of the cashew tree (Anacardium occidentale). Cashews are considered a "healthy" food because of their monounsaturated fat content that is similar to olive oil. Nuts, despite their overall healthy nutrient profile, have substantial amounts of oxalate.

The oxalate content of cashews is moderate ${ }^{9}$ compared with other nuts; however, by consuming large amounts daily, the patient increased her total daily intake of oxalate to a level much higher than average (Box 1). ${ }^{10}$ In addition, her lower calcium intake promoted hyperabsorption of oxalate, because calcium was not available to bind oxalate in the gut. Furthermore, the higher fat content of cashews (about $45^{\circ} \%$ ), although healthy for the heart, perpetuated oxalate absorption by further reducing the calcium available to bind oxalate in the gut. All of these factors and possibly the higher concentration of intestinal soluble oxalate ${ }^{11}$ promoted hyperabsorption of oxalate, which resulted in increased urinary oxalate concentration, with precipitation of calcium oxalate crystals in the renal tubules causing kidney injury.

\section{Nephrolithiasis versus nephropathy}

The exact mechanism of why kidney stones develop in some patients with hyperoxaluria and kidney injury in others is unknown and possibly multifactorial. However, recent evidence suggests that supersaturation of soluble oxalate causes increased expression of nucleotide-binding oligomerization domain-like receptor, pyrin domain 3 (NLRP3) inflammasomes in the kidney that trigger inflammation and potential kidney injury that may be acute or chronic ${ }^{12}$ rather than stone formation (nephrolithiasis).

\section{Management}

Prevention is key, and foods rich in oxalate content should be consumed with caution. Even foods that are moderate in oxalate content may cause kidney injury, especially if dietary calcium intake is poor; oxalate bioavailability plays an important role. ${ }^{6,7}$

Therapeutic options are extrapolated from studies in patients with primary hyperoxaluria and oxalate stones. Based on expert opinion, conservative measures should be implemented soon after diagnosis and include a diet low in oxalate and relatively high in calcium, maintenance of high fluid intake (at least $1.5 \mathrm{~L}$ per $1.73 \mathrm{~m}^{2}$ per day) and consideration of potassium citrate to alkalinize urine to increase solubility of oxalate crystals. ${ }^{13}$ The role of probiotics is controversial, with studies showing conflicting results.

\section{Conclusion}

Crystalline nephropathies should be considered in the differential diagnosis of patients with unexplained renal dysfunction. A detailed dietary history may provide a clue to the cause, as in this patient's case, and measures to control reversible factors should be implemented at the earliest opportunity to prevent further progression. 


\section{References}

1. Siener R, Hesse A. The effect of different diets on urine composition and the risk of calcium oxalate crystallisation in healthy subjects. Eur Urol 2002;42:289-96.

2. Bhasin B, Urekli HM, Atta MG. Primary and secondary hyperoxaluria: understanding the enigma. World J Nephrol 2015;4:235-44.

3. Glew RH, Sun Y, Horowitz BL, et al. Nephropathy in dietary hyperoxaluria: a potentially preventable acute or chronic kidney disease. World J Nephrol 2014;3:122-42.

4. Kumar R, Lieske JC, Collazo-Clavell ML, et al. Fat malabsorption and increased intestinal oxalate absorption are common after Roux-en-Y gastric bypass surgery. Surgery 2011;149:654-61.

5. Wake Forest Baptist Health. Oxalate content of foods. 2016; Winston-Salem (NC): Wake Forest Baptist Medical Center. Available: www.wakehealth.edu/Urology/ Kidney-Stones/Oxalate-Content-of-Foods.htm (accessed 2016 Feb. 20).

6. Liebman M, Chai W. Effect of dietary calcium on urinary oxalate excretion after oxalate loads. Am J Clin Nutr 1997;65:1453-9.
7. Zimmermann DJ, Voss S, von Unruh GE, et al. Importance of magnesium in absorption and excretion of oxalate. Urol Int 2005;74:262-7.

8. Getting JE, Gregoire JR, Phul A, et al. Oxalate nephropathy due to 'juicing': case report and review. Am J Med 2013;126:768-72.

9. Chai W, Liebman M. Oxalate content of legumes, nuts, and grain-based flours. J Food Compos Anal 2005;18:723-9.

10. Holmes RP, Kennedy M. Estimation of the oxalate content of foods and daily oxalate intake. Kidney Int 2000;57:1662-7.

11. Ritter MMC, Savage GP. Soluble and insoluble oxalate content of the nuts. J Food Compos Anal 2007;20:169-74.

12. Knauf F, Asplin JR, Granja I, et al. NALP3-mediated inflammation is a principa cause of progressive renal failure in oxalate nephropathy. Kidney Int 2013; 84:895-901.

13. Hoppe B, Leumann E. Diagnostic and therapeutic strategies in hyperoxaluria: a plea for early intervention. Nephrol Dial Transplant 2004;19:39-42.

\section{Competing interests: None declared.}

This article has been peer reviewed.

The authors have obtained patient consent.

Affiliations: Timmins and District Hospital (Bernardino, Parmar), Timmins, Ont.; Division of Clinical Sciences (Parmar), Northern Ontario School of Medicine, Sudbury and Thunder Bay, Ont.
Contributors: Malvinder Parmar conceived the idea and prepared the initial draft. Margarida Bernardino reviewed the patient's diet in detail for oxalate content. Both authors revised the manuscript, reviewed it critically for important intellectual content and agreed to act as guarantors of the work.
Acknowledgement: The authors thank Dr. Rohan John, Associate Professor, Department of Pathology, University Health Network, Toronto, for providing photomicrographs of the kidney biopsy of this patient.

Correspondence to: Malvinder S. Parmar, wittykidney@gmail.com 